\title{
Teste de Alfabetização Científica Básica: PROCEsSo de REDUÇÃo E VALIDAÇÃo do INSTRUMENTO NA LÍNGUA PORTUGUESA
}

\author{
TEST OF BASIC SCIENTIFIC LITERACY: REDUCTION AND VALIDATION \\ PROCESS FOR THE PORTUGUESE TRANSLATION INSTRUMENT
}

DOI: http://dx.doi.org/10.23926/RPD.2526-2149.2018.v3.n2.p575-594.id251

\author{
Patrick Alves Vizzotto \\ Mestre em Educação em \\ Ciências (FURG). \\ Professor EBTT (IFSUL). \\ Doutorando em Educação \\ em Ciências (UFRGS). \\ patrick.vizzotto@ufrgs.br
}

\section{Luiz Fernando \\ Mackedanz}

Doutor em Ciências

(UFRGS).

Professor do Instituto de

Matemática, Estatística e

Física (FURG).

luismackedanz@furg.br
Resumo: Este estudo teve por objetivo apresentar o processo de redução instrumental do Teste de Alfabetização Científica Básica (TACB), de Laugksch e Spargo (1996). Este instrumento, de referência na literatura nacional e internacional, é constituído por 110 questões que versam sobre conceitos e fenômenos científicos, natureza da ciência e impactos da ciência e tecnologia sobre a sociedade e ambiente. O seu tamanho pode inviabilizar a aplicação dentro do contexto escolar, pois é necessário grande tempo para respondê-lo e, por isso, corre-se o risco de comprometer o compromisso dos participantes para com as respostas assinaladas. Uma possibilidade de solução é reduzi-lo para um número menor de itens, por meio de técnicas estatísticas, sem que sua validade, confiabilidade e poder de medida sejam prejudicados. Para isso, uma aplicação do TACB foi realizada no primeiro semestre de 2018 em 141 indivíduos, egressos do Ensino Médio, ingressantes de um Instituto Federal da cidade de Pelotas/RS. Como resultados, obteve-se uma redução para 45 itens, mantendo semelhantes os índices de validação do instrumento original. Espera-se que este instrumento possa contribuir com docentes e pesquisadores da área, auxiliando-os na apresentação de diagnósticos sobre a Alfabetização Científica no contexto brasileiro.

Palavras-chave: Letramento Científico. Educação em Ciências. Confiabilidade.

\begin{abstract}
This study aimed to present the process of reducing instrumental Test of Basic Scientific Literacy (TBSL) of Laugksch and Spargo (1996). This instrument, with reference in national and international literature, consists in 110 questions relating concepts and scientific phenomena, the nature of science and impacts of science and technology on society and on the environment. The questionnaire size can derail the application on school context, because it requires large time to answer it, and also there is a risk of compromising the participant's commitment about the marked answers. A possible solution is to reduce it to a smaller number of items, by using statistical techniques, so that the validity, reliability and power of measurement wouldn't be harmed. Then, an application of the TBSL was held in the first half of 2018 in 141 individuals, graduates from high school, entering a Federal Institute of the city of Pelotas/RS. As a result, it got a reduction to 45 items, keeping similar validation indexes of the original instrument. It is expected that this instrument can contribute with teachers and researchers, assisting them to present diagnostics about the Scientific Literacy in Brazilian context.
\end{abstract}

Keywords: Scientific Literacy. Science Education. Reliability. 


\section{INTRODUÇÃO}

No cenário atual, assumimos que um dos (muitos) papéis da escola é formar um cidadão preparado para atuar dentro do seu cotidiano de forma crítica. Dentro das disciplinas de ciências, acredita-se que estes objetivos vão ao encontro do que é defendido pela Alfabetização Científica (AC). Um indivíduo considerado alfabetizado cientificamente, segundo Miller (1983), não é só aquele que entende os conceitos científicos, as nomenclaturas e relações históricas de tal conhecimento, mas sim aquele que, além disso, compreende como o conhecimento científico é produzido e também o impacto que a ciência e suas tecnologias produzem na sociedade e meio ambiente.

$\mathrm{O}$ ato de mensurar o nível de Alfabetização Científica de uma pessoa é uma tarefa desafiadora, realizada por poucos autores da área. Um estudo proeminente realizado por Laugksch e Spargo (1996), obteve êxito em buscar formas de alcançar tal objetivo. Estes autores elaboraram um questionário denominado de Test of Basic Scientific Literacy - TBSL, com base nos três eixos estruturantes da Alfabetização Científica, postulados por Miller (1983): o entendimento de conceitos, termos técnicos e científicos; o entendimento da natureza da ciência; e a compreensão referente ao impacto da ciência e da tecnologia sobre a sociedade.

Este tem se consolidado como o instrumento de referência utilizado em diversos países ao redor do mundo para avaliar o grau de AC de forma quantitativa, conforme os trabalhos na África do Sul (LAUGKSCH; SPARGO, 1996; 1999); Austrália (MURCIA; SCHIBECI, 1999); China (CHIN, 2005); Israel (BARAM-TSABARI; YARDEN, 2005); Brasil (CAMARGO; BARBARÁ; BERTOLDO, 2005; NASCIMENTO-SCHULZE， 2006); Estados Unidos (BROSSARD; SHANAHAN, 2006); Turquia (ÖZDEM, 2010).

Porém, tanto os autores como outros pesquisadores que fizeram uso do TBSL em seus trabalhos, relataram que o fato dele ser um questionário extenso, contendo 110 itens, pode tornar $\mathrm{o}$ ato de respondê-lo uma tarefa enfadonha. Tal consequência pode lesar o comprometimento dos respondentes prejudicando, assim, a confiabilidade da medida. Sendo assim, o objetivo deste artigo é apresentar o processo de redução deste instrumento, com base em métodos estatísticos, assegurando, por meio de testes de consistência interna e correlação, a mesma capacidade de medida, porém com um instrumento simplificado. Observa-se este procedimento, principalmente em trabalhos da área da saúde (ANDRADE; SCHEUER, 2004; BITTAR et. al., 2006; FRANCA; COLARES, 2010), os quais buscam diminuir a quantidade de itens de um questionário de referência, mantendo uma análise válida e confiável a partir de um 
instrumento com menor quantidade de itens do que o seu original. Isto pode trazer agilidade na identificação de patologias, pois reduz o tempo necessário para se realizar um diagnóstico.

Dentro da Educação em Ciências, este trabalho visa colaborar com a literatura da área por proporcionar uma alternativa de questionário que viabilize, em termos práticos, sua aplicação em ambiente escolar, pois de forma diretamente proporcional ao número de itens, está o tempo que os indivíduos demoram em respondê-lo, o que, muitas vezes, ultrapassa o período de uma aula escolar. Estas dificuldades inviabilizam sua aplicação, tanto para professores que desejam saber uma medida tangível sobre a AC de seus alunos, quanto para pesquisadores que poderiam o utilizar para aprofundar o estado da arte da área.

Sendo assim, o artigo está estruturado no seguinte formato: primeiro, realiza-se uma revisão sobre a $\mathrm{AC}$, discutindo aspectos sobre a sua nomenclatura e o processo utilizado para mensurá-la. Em um segundo momento, é explicada a metodologia empregada para o processo de redução do TACB, sendo seguido pela apresentação dos resultados e suas discussões.

\section{A Alfabetização Científica e a sua mensuração}

Espera-se que, ao concluir a Educação Básica, os egressos possuam competências que os permitam compreender e atuar em seus cotidianos de forma crítica e responsável. De modo geral, a Alfabetização Científica compartilha desse objetivo e este ideal corrobora para que as disciplinas científicas possam contribuir de modo significativo para este processo.

O conhecimento científico, assim como os demais tipos de conhecimento, mostra-se imprescindível para uma efetiva leitura crítica do cotidiano, sendo indispensável para compreender fenômenos da natureza, assim como contribui para a percepção de aspectos sóciocientíficos presentes em decisões políticas que influenciam a sociedade e trazem impactos ao meio ambiente (MAMEDE; ZIMMERMANN, 2005; RIVAS, 2015).

Considerando a importância de que tais competências sejam desenvolvidas com êxito nos indivíduos que passam pela escola, é fundamental questionar se os assuntos abordados dentro das aulas de Ciências da Natureza durante toda a Educação Básica contribuem, de fato, para a AC dos egressos. Não se deve refletir somente sobre os assuntos que fazem parte dos currículos, pois o modo com que eles são abordados em sala de aula também influencia de forma significativa a assimilação do conhecimento escolar.

Para Chassot (2011), há um distanciamento entre a linguagem do professor e a dos alunos, assim como a forma com que os conteúdos de ciências são socializados no cotidiano da sala de aula, sendo necessário migrar o conhecimento que atualmente apresenta-se de forma 
hermética, codificada, "esotérica", para um modo "exotérico", ou seja, aberto, acessível, compreensível por todos os que buscam compreendê-lo.

Desse modo, acredita-se que entender a natureza da ciência também pode colaborar para a AC, assim como também é importante que se aprenda a manipular artefatos cotidianos, como os objetos tecnológicos, mas não limitados a isso. Além de compreender as leis da física e suas aplicações, um indivíduo alfabetizado cientificamente é aquele que compreende os impactos da ciência e da produção de tecnologia no ambiente e na sociedade.

Atualmente, acredita-se que o conhecimento científico não está presente na cultura geral, mesmo que dispositivos tecnológicos sejam utilizados de forma exaustiva em praticamente todos os setores do cotidiano.

Para Souza et al. (2007, p. 77),

\begin{abstract}
As pessoas têm algo a dizer sobre questões relacionadas ao futebol, à religião e a tantos outros assuntos que se fazem presentes no nosso dia-a-dia. Por outro lado, quando questionadas a respeito de algo relacionado à ciência e tecnologia, as pessoas não se envergonham em dizer o quanto desconhecem o assunto. A pior situação vivida é quando as pessoas afirmam que isso é assunto para o 'povo da ciência'.
\end{abstract}

A simples presença dos componentes tecnológicos na vida das pessoas não significa que o entendimento dos mesmos faça parte de sua cultura. Aprender a manipulá-los não significa que automaticamente o conhecimento sobre a ciência e tecnologia presente neles será desvendada e compreendida pelos usuários.

A própria nomenclatura desta linha de investigação é objeto de expressiva discussão dentro da literatura da área. Alguns trabalhos denominam de Alfabetização Científica, outros de Letramento Científico e outros ainda, de Enculturação Científica. Cada autor utiliza-se de bases da linguística para justificar a escolha de um ou outro termo.

Observa-se que atualmente a maioria dos trabalhos vinculados em mecanismos de buscas acadêmicas utilizam a Alfabetização Científica como descritor, sendo seguidas de Letramento Científico e por fim, Enculturação Científica. Uma busca na base do Google Acadêmico em 2018, utilizando a expressão Alfabetização Científica, revelou 25.800 resultados, enquanto que com o termo Letramento Científico, os resultados foram de 17.900 trabalhos, sendo seguida pela Enculturação Científica, com 11.700 resultados.

Estes quantitativos revelam que em quatro anos, o número de trabalhos recuperados pelo descritor Alfabetização Científica aumentou mais de seis vezes o número obtido em 2014, que segundo Cunha (2017) foi de 4.180. Por sua vez, na época, a busca por Letramento Científico 
apresentou 714 resultados, ou seja, atualmente o número de trabalhos recuperados para este descritor é vinte e cinco vezes maior.

A variação dos termos advém do processo de tradução para a língua portuguesa do termo Scientific Literacy. Este, surgiu em 1958 em um trabalho escrito por Paul Hurd, intitulado "Scientific Literacy: Its Meaning for American Schools". O ideário do termo foi difundido e abordado em trabalhos na língua inglesa, francesa, espanhola, assim como também foi escrito em trabalhos em português. No entanto, alguns autores optaram, pela tradução literal dos termos, adotando assim a nomenclatura Letramento Científico. Em francês, a terminação é denominada de Alphabétisation Scientifique e em espanhol, Alfabetización Cientifica, sendo que ambas podem ser traduzidas para o português como Alfabetização Científica. Há ainda, conforme referido, autores que preferem o termo Enculturação, pois defendem que os objetivos defendidos por esta linha de investigação envolvem todo um processo de criar uma cultura científica, para assim, os ideais obterem êxito (MORTIMER; MACHADO, 1996; CARVALHO; TINOCO, 2006).

Considera-se a observação de Sasseron e Carvalho (2011, p. 75) na qual afirmam que:

Percebemos que, tanto em âmbito internacional, com os trabalhos sobre "scientific literacy", "alfabetización cientifica", "alphabétisation scientifique", como em âmbito nacional, com pesquisas sobre o "letramento científico", "alfabetização científica" e "enculturação científica", estão em concordância no que diz respeito às finalidades almejadas hoje em dia com a educação científica.

Tais finalidades citadas pelas autoras consistem no domínio, por parte da população, de conhecimentos básicos sobre ciência, a fim de capacitar os indivíduos a atuarem na sociedade de forma responsável e crítica, possibilitando com que se posicionem acerca de questões relativas a políticas científicas "garantindo às ações governamentais voltadas para a ciência uma natureza democrática com participação efetiva dos cidadãos" (Nascimento-Schulze et al., 2006, p. 26). Para Chassot (2003), é possível considerar estes termos como o conjunto de conhecimentos que possibilitaria ao ser humano fazer uma leitura do mundo no qual vivem.

O debate sobre o significado dos três termos considera que a Alfabetização Científica seria a "aprendizagem dos conteúdos e linguagem científica, enquanto que o Letramento Científico, seria referente ao uso, num contexto sócio-histórico específico, do conhecimento científico e tecnológico no cotidiano do indivíduo" (VIDOR et al., 2009, p. 2).

Segundo Cunha (2017), o termo Letramento surgiu em trabalhos brasileiros na década de 1980, a fim de "distinguir entre o mero aprendizado da codificação da escrita, a alfabetização, e o impacto de seu efetivo uso em práticas sociais” (p. 172). Esta diferenciação 
teve por objetivo delimitar diferenças fundamentais, principalmente advindas da base linguística. Tal fundamentação demonstra que a alfabetização faz referência à habilidades e saberes que dão base à leitura e escrita, sendo este processo, individual. O letramento, por sua vez, refere-se às práticas de leitura e escrita no âmbito social. Desse modo, um indivíduo letrado não somente saberia interpretar e decodificar a linguagem, mas também a utilizaria de modo efetivo dentro de situações da vida social, compreendendo a significação além da linguagem em si, o que nem sempre aconteceria com alguém apenas alfabetizado.

Para Mamede e Zimmermann (2005), transpondo esta diferenciação para o âmbito científico, a Alfabetização Científica, consistiria na aprendizagem dos conteúdos e da linguagem científica, enquanto que o Letramento Científico, faria referência à habilidade de utilizar este conhecimento científico e tecnológico no cotidiano, inserido dentro de um contexto sócio-histórico particular.

Sobre esta discussão, corroboramos as ideias de Auler e Delizoicov (2001), quando defendem que a alfabetização não pode se configurar como um jogo mecânico de juntar letras. Alfabetizar é muito mais do que ler palavras, ela deve propiciar a "leitura do mundo". Sendo assim, um indivíduo alfabetizado cientificamente é aquele que demonstra competência de utilizar seus saberes para compreender e atuar em seu cotidiano de forma crítica, mobilizando seus conhecimentos e experiências a fim de que suas decisões sejam tomadas com consciência das relações de causa e efeito que elas podem desencadear.

Após o surgimento do conceito de Alfabetização Científica em 1958, em poucas décadas, observou-se um aumento no interesse dos pesquisadores no tema, o que resultou em uma expressiva quantidade de publicações na área da Educação em Ciências. Analisando o fenômeno e buscando subsídios para fundamentar os elementos que seriam importantes um indivíduo compreender para ser considerado alfabetizado cientificamente, Miller (1983) postulou que para tal, deve haver o domínio de três eixos distintos, chamados de eixos estruturantes da Alfabetização Científica, já citados anteriormente.

Para o autor, é imprescindível a alguém alfabetizado cientificamente compreender os conceitos e termos utilizados dentro das ciências da natureza, constituindo este, o primeiro eixo. Desta maneira, é possível que estes conhecimentos sejam percebidos dentro de situações cotidianas. Este eixo engloba conhecimentos referentes à filosofia e história da ciência, a linguagem científica, o conhecimento dos conceitos e sua linguagem. A proficiência neste eixo pode proporcionar criticidade para analisar a ciência aplicada à vida e também a tomada de decisão responsável por parte do cidadão. 
O segundo eixo, denominado "entendimento da natureza da ciência" tem sua importância, pois esta concepção permite com que o cidadão possa compreender as normas e métodos utilizados para a construção do conhecimento científico, assim como as questões éticas e políticas que influenciam esta área. Isto permite com que a ciência seja compreendida como um conjunto de conhecimentos em construção e transformação, e não algo absoluto, dogmático e certo, determinado por algumas pessoas e sem possibilidade de mudança. Este eixo também é importante, segundo Sasseron e Carvalho (2011), pois ele fornece subsídios para que o caráter humano e social presente nas investigações cientificas seja compreendido e também questionado. "Além disso, deve trazer contribuições para o comportamento assumido por alunos e professor, sempre que defrontados com informações e conjuntos de novas circunstâncias que exigem reflexões e análises considerando-se o contexto antes de tomar uma decisão" (SASSERON; CARVALHO, 2011, p. 75).

O terceiro eixo estruturante refere-se ao "entendimento do impacto da ciência e da tecnologia sobre a sociedade e meio-ambiente". A ciência não é neutra, e suas ações impactam tanto a sociedade quanto o ambiente no qual ela está inserida. Portanto, compreender estas relações colabora para o perfil de um indivíduo alfabetizado cientificamente, pois é necessário perceber que sempre que em uma solução para um problema atual não houver reflexão sobre os impactos desta ação, esta pode gerar outro problema associado no futuro. A compreensão de que a ciência não está dissociada de um contexto e imune a consequências, é fundamental para uma compreensão abrangente do trabalho e da importância desta para o ser humano e para o planeta. Logo "o trabalho com este eixo deve ser garantido na escola quando se tem em mente o desejo de um futuro sustentável para a sociedade e o planeta" (SASSERON; CARVALHO, 2011, p. 75).

O segundo e terceiro eixos envolvem discussões de aspectos sócio-científicos, sendo estes assuntos de caráter social, cultural, político, econômico e ambiental, ligados à prática científica, assim como valores atrelados à essas práticas.

Rivas (2015) e Camargo et al. (2011), demonstram indícios de que a escola esteja priorizando apenas o primeiro eixo, de forma conteudista e em muitas vezes permeado pelos chamados mitos cientificistas (AULER; DELIZOICOV, 2001). Somente a abordagem dos conteúdos e linguagem da ciência não contribui para uma AC efetiva, pois pouco auxilia na construção da criticidade dos indivíduos. Isto acontece devido à memorização desconexa de termos atribuídos ao conhecimento científico, fazendo do contexto por trás da construção deste saber, algo hermético e oculto ao que é ensinado. 
Assim como Miller (1983) postulou os três eixos descritos na década de 1980, no Brasil, Sasseron e Carvalho (2008) corroboram a composição da Alfabetização Científica dentro destas subdivisões, replicando a difusão da importância da apropriação destas três esferas para considerar um indivíduo proficiente cientificamente.

Embora se encontre um número significativo de trabalhos sobre Alfabetização Científica e de seus termos correlatos, é pequeno o número de trabalhos que se proponham a mensurar o nível de Alfabetização Científica de um indivíduo. Acredita-se que identificar tais níveis, embora seja uma tarefa complexa, possa auxiliar a orientar a prática pedagógica, assim como a sua avaliação, pois pode "trazer à tona problemas e expectativas do ensino de ciências no Brasil" (LIMA; WEBER, 2017, p. 2). Segundo os autores, a maioria dos trabalhos na temática é composta por revisões bibliográficas ou propostas metodológicas para ensinar na perspectiva da Alfabetização Científica, revelando a carência desse tipo de estudo de mensuração.

Em nível internacional, as primeiras iniciativas com o objetivo de estimar tais níveis em egressos da escola básica surgiram depois da contribuição supracitada dos eixos que compõe a Alfabetização Científica (RIVAS, 2015). Na maioria dos resultados, concluiu-se que os níveis observados foram abaixo do esperado para o público-alvo analisado, uma vez que

\begin{abstract}
Pesquisas que tiveram por objetivo principal a mensuração da alfabetização científica em vários países indicam que uma pequena proporção dos sujeitos estudados possui uma capacitação mínima para entender os termos e processos da ciência. Miller (2000a; 2000b) verificou que apenas $11 \%$ dos norte-americanos adultos poderiam ser considerados alfabetizados cientificamente. Na África do Sul, Laugksch e Spargo (1999) encontraram uma proporção básica de alfabetização científica em 36\% de uma amostra representativa de alunos que haviam concluído o ensino secundário. Nascimento-Schulze (2006) encontrou uma proporção semelhante, 36,5\%, entre estudantes do estado de Santa Catarina; e, ao mensurar a alfabetização científica de 63 professores de ciências de colégios públicos e particulares de Santa Catarina, deparou-se com a realidade de que cerca de um quinto da amostra poderia ser considerado como não alfabetizado cientificamente. (NASCIMENTO-SCHULZE, 2006, p. 26).
\end{abstract}

Laugksch e Spargo (1996) elaboraram um questionário denominado Test of Basic Scientific Literacy (TBSL), com 110 questões dicotômicas, a fim de mensurar o nível de AC de egressos do Ensino Médio. As questões versam sobre aspectos mínimos que um egresso da Educação Básica deveria possuir para ser considerado alfabetizado cientificamente. Tal instrumento de pesquisa foi validado estatisticamente e aplicado a mais de 4.000 egressos da Educação Básica no momento em que estavam ingressando na universidade.

Segundo Rivas (2015), o TBSL é um importante instrumento para mensurar e comparar o nível de AC, podendo ser utilizado em diversos grupos diferentes, desde alunos, egressos da 
escola até professores, cientistas e consumidores. Por ser um teste que mensura aspectos básicos, as questões englobam assuntos das Ciências Exatas, Ciências da Saúde, Ciências Biológicas, assim como os eixos da natureza da ciência e do impacto da ciência e tecnologia na sociedade.

No Brasil, o TBSL foi traduzido por Nascimento-Schulze (2006), aplicando o instrumento com alunos e professores da educação básica de Santa Catarina. Este teste, na língua portuguesa, foi denominado Teste de Alfabetização Científica Básica - TACB. A partir desta inciativa, outros trabalhos foram produzidos, aplicando o instrumento em diversos contextos.

Rivas (2015), por exemplo, obteve resultados que apontaram como eixo de melhor desempenho dos respondentes aquele que avalia o conteúdo da ciência e que as questões de pior desempenho eram as relacionadas a temas de Física, sendo que "mais da metade dos participantes demonstrou não compreender de modo satisfatório a $1^{\mathrm{a}}$ Lei de Newton" (p. 13). Isto evidencia que os outros eixos, com questões sobre a natureza da ciência e impactos da ciência na sociedade não obtiveram igual desempenho, sinalizando uma possível ênfase na natureza conteudista do ensino de ciências atual, o que também é corroborado por Camargo et al. (2012).

Por sua vez, Nascimento-Schulze (2006) observou que alunos da rede pública obtiveram desempenho estatisticamente inferior, quando comparados com alunos de escolas particulares. De forma surpreendente, a autora constatou que essa diferença também foi percebida com os professores desses alunos, havendo uma ligeira diferença estatisticamente considerável entre professores do ensino público e do ensino privado.

Embora alguns estudos tenham se dedicado a mensurar os níveis de Alfabetização Cientifica, com destaque aos que utilizaram o TBSL, os autores recomendam que mais estudos sejam realizados, tanto de validação do instrumento em diversos públicos-alvo do contexto brasileiro, como em um aumento na quantidade de respondentes.

Autoras como Nascimento-Schulze (2006) reconhecem que a extensão do teste é um fator que dificulta sua aplicação para um número maior de indivíduos. Um questionário com 110 questões, mesmo com itens dicotômicos, torna-se enfadonho para os respondentes, trazendo certo viés nas respostas, assim como a possibilidade de marcar alternativas aleatórias, a fim de apenas concluir a atividade. Esta ação compromete a confiabilidade do instrumento. Conclui-se então, que é relevante e necessário estudos estatísticos de redução instrumental. 
É com base nesta dificuldade que este estudo foi motivado. Apresentamos na sequência, os procedimentos metodológicos que tiveram por objetivo reduzir a quantidade de itens do TACB, sem perda de seu poder de mensuração. Por meio de técnicas de estatística inferencial, a redução foi realizada e a sua consistência interna atestada para um instrumento de maior viabilidade de ser utilizado no cotidiano do professores e pesquisadores da área.

\section{Metodologia}

O Teste de Alfabetização Científica Básica (TACB) é subdivido nos três eixos estruturantes da Alfabetização Científica (MILLER, 1983), sendo que para um respondente ser considerado alfabetizado cientificamente, deve obter êxito em um mínimo de acertos das três subdivisões. De modo geral, é necessário acertar em torno de $60 \%$ de cada subteste. Se em algum dos subtestes o mínimo não for atingido, este respondente não poderá ser considerado como alfabetizado cientificamente.

Todo questionário deve apresentar características de validade e confiabilidade para ser considerado apto a aplicações. Para garantir que um instrumento de coleta de dados meça o que se propõe a medir, é importante o elaborador atestar a sua validade. Por exemplo, um instrumento válido para medir conhecimento prévio deve mensurar realmente esta característica e não outra, como por exemplo, interpretação de texto. Então, atestando tal coerência, pode-se considerá-lo como válido. A validade geralmente é atestada mediante a análise dos itens, realizada por um grupo de especialistas. Estes avaliam desde aspectos semânticos até mesmo consistências teóricas dos mesmos.

A confiabilidade, por sua vez, atesta que os resultados serão semelhantes se aplicados em uma mesma pessoa em tempos diferentes. Para Figueiredo et al. (2008), há diversas técnicas para realizar tal teste, porém em pesquisa com seres humanos, reproduzir as mesmas condições em dois momentos diferentes é algo praticamente impossível. Considerando esta dificuldade, Moreira e Rosa (2007) salientam que uma das maneiras de calcular esta estimativa é determinar a consistência interna do instrumento em questão. A consistência interna aponta se todos os itens de um questionário medem a mesma característica.

De acordo com Souza et al. (2017), geralmente a consistência interna é aferida através do cálculo do coeficiente Alfa de Cronbach, o qual demonstra o grau de variância entre os itens do questionário. Isto significa que quanto menor a soma da variância, mais consistente o instrumento pode ser considerado. Como é um coeficiente, o mesmo, apresenta valores de 0 a 1, e quanto mais próximo de 1 for o resultado, maior sua avaliação como consistente, embora 
valores a partir de 0,60 e 0,70 já sejam aceitáveis pela literatura da área (HAIR et al., 2006; PASQUALI, 2017). Particularmente, para questionários que apresentam opções dicotômicas de resposta, como no caso do TACB, a consistência interna é avaliada pelo coeficiente de KuderRichardson, um caso específico do Alfa de Cronbach, particular para este formato de respostas.

Como os aspectos de validade dos itens já foram analisados, tanto durante a criação do instrumento (LAUGKSCH; SPARGO,1996), quanto no seu processo de tradução para a língua portuguesa (NASCIMENTO-SCHULZE, 2006), este artigo se concentrará no processo de redução, atestando seu êxito por meio do teste de confiabilidade supracitado e também na análise da correlação entre os índices de acertos do questionário integral e reduzido.

O valor de consistência interna de um determinado instrumento está associado a certa confiabilidade de medida. Ao procedermos a redução do instrumento, temos como objetivo reduzir apenas a quantidade de itens e não o seu poder de mensuração. Por isso, é fundamental que o índice de consistência interna do instrumento não diminuía significativamente seu valor durante a redução de itens. Ou seja, as questões que fizerem parte do instrumento reduzido devem proporcionar valor semelhante ou maior de confiabilidade para o questionário como um todo (PASQUALI, 2017).

Porém, a confiabilidade afere apenas a consistência do instrumento. Para atestar que o questionário reduzido possui o mesmo poder de medida em relação ao questionário integral, é necessário observar se o índice de acertos de um mesmo respondente é semelhante em ambos instrumentos. Para isso, testa-se o grau de correlação entre a quantidade de respostas corretas do questionário integral e a respectiva quantidade de acertos para a sua forma reduzida. Esperase que um instrumento reduzido, com capacidade de medida semelhante ao instrumento integral, ofereça um alto grau de correlação entre eles.

Para efetuar tais medidas, será utilizado o Teste de Correlação de Pearson, que é utilizado para medir a correlação entre duas variáveis (HAIR et al., 2006; PASQUALI, 2017). Segundo os autores, o grau de correlação de Pearson gera um número entre - 1 e 1 e quanto mais próximo de 1, mais significativa é a correlação. Valores de correlação entre 0,5 a 0,7 indicam uma correlação moderada, de 0,7 a 0,9, correlação forte, e de 0,9 a 1, significa uma correlação muito forte. Nesta análise, ao comparamos nosso instrumento reduzido com o original, adotamos que ambos possuem semelhante poder de medida quando a correlação for considerada, no mínimo, como forte, para cada um dos subtestes, bem como para o questionário como um todo. 
Para realizar o procedimento de redução, primeiramente o instrumento completo foi aplicado para 141 indivíduos egressos do Ensino Médio, alunos de cursos do Ensino Superior de um Instituto Federal da cidade de Pelotas/RS. A aplicação ocorreu durante o primeiro semestre de 2018, nas aulas de Física, e os respondentes demoraram um tempo médio de 50 minutos para respondê-lo. O questionário era anônimo e a participação dos alunos não foi obrigatória, sendo que a qualquer momento os participantes poderiam decidir deixar de fazer parte da pesquisa. Os mesmos assinaram um termo de consentimento livre e esclarecido, que assegurava as informações sobre a pesquisa, bem como a preocupação dos pesquisadores para com o uso adequado dos dados coletados, mesmo que o instrumento não solicitasse informações de identificação.

A seguir, as respostas foram conferidas e tabeladas em um documento eletrônico para posterior análise em software estatístico. Para realização do procedimento de análise, utilizamos o Statistical Package for the Social Sciences - SPSS ${ }^{\circledR}$, versão 23 para Windows. Conforme nossas discussões prévias, os valores de saída utilizados para a redução do questionário foram o coeficiente Kuder-Richardson (que representa a consistência interna do instrumento) e a análise da correlação item-total de cada questão, que exibe o quanto o item está correlacionado com o instrumento como um todo. Por isso, itens que colaboram para um alto valor de fidedignidade, terão também um alto coeficiente de correlação item-total. Por outro lado, um item que não se adequa à escala deve apresentar uma baixa correlação item-total (HAIR et al., 2006). Ao constatarmos tais itens, precisamos verificar se a consistência interna do instrumento aumenta com a remoção do mesmo. Ao fim do processo de redução, testamos a correlação da quantidade de acertos para o instrumento integral e para o reduzido, a fim de observar se o padrão de respostas segue uma tendência semelhante em ambos os instrumentos.

\section{Resultados}

Considerando que o TACB é composto por três subtestes, que medem os três eixos estruturantes da Alfabetização Científica (MILLER, 1983), as análises a seguir serão também realizadas de forma separada para cada subtestes, de forma similar ao instrumento integral.

Primeiramente, calculamos a consistência interna para o questionário como um todo. $\mathrm{O}$ valor do coeficiente de Kuder-Richardson foi de 0,841, considerado satisfatório para a fidedignidade. Em um segundo momento, calculamos, para cada subteste, os respectivos coeficientes. Para o eixo "entendimento do conteúdo da ciência", o valor obtido foi 0,819 ; no eixo "entendimento da natureza da ciência", foi 0,405; e no eixo "entendimento do impacto da 
ciência e tecnologia na sociedade", foi 0,369 . Percebe-se que, de forma separada, apenas o primeiro eixo possui um valor satisfatório para sua consistência interna. Um dos motivos que podem auxiliar na explicação deste fenômeno é o número pequeno de itens dos eixos restantes, pois o segundo eixo contém 22 itens e o terceiro eixo, 16.

Avaliados estes valores, passamos à análise dos itens de cada eixo, buscando identificar quais deles contribuem para a baixa fidedignidade geral do instrumento. Realizada esta análise, a consistência interna será calculada novamente para cada eixo e para o questionário integral, a fim de verificar se houve estabilidade ou aumento deste índice.

No Quadro 1, apresentamos a correlação item-total para o eixo "entendimento do conteúdo da ciência”. Para este eixo, adotou-se um limite de correlação aceitável de 0,250. Com base nesta análise, se pode notar que 45 questões estão colaborando pouco ou até mesmo de forma negativa com este eixo. Ou seja, optou-se por verificar se removendo itens com correlação abaixo deste valor estipulado, a confiabilidade do teste se mantém. Realizado o novo teste, o valor apresentado foi de 0,806 , demonstrando que mesmo removendo 45 questões deste subteste, ele se mantém consistente com 27 questões.

Quadro 1 - Correlação item-total para o primeiro eixo.

\begin{tabular}{|c|c|c|c|c|c|c|c|}
\hline Item & $\begin{array}{c}\text { Correlação } \\
\text { de item total }\end{array}$ & Item & $\begin{array}{c}\text { Correlação } \\
\text { de item total }\end{array}$ & Item & $\begin{array}{c}\text { Correlação } \\
\text { de item total }\end{array}$ & Item & $\begin{array}{c}\text { Correlação } \\
\text { de item total }\end{array}$ \\
\hline 84 &, 495 & 107 &, 284 & 78 &, 215 & 2 &, 142 \\
\hline 38 &, 472 & 41 &, 279 & 55 &, 214 & 9 &, 141 \\
\hline 82 &, 445 & 90 &, 275 & 13 &, 204 & 88 &, 137 \\
\hline 106 &, 441 & 3 &, 272 & 91 &, 204 & 9 &, 136 \\
\hline 44 &, 418 & 5 &, 259 & 104 &, 202 & 56 &, 132 \\
\hline 92 &, 391 & 43 &, 259 & 46 &, 198 & 11 &, 128 \\
\hline 105 &, 367 & 59 &, 258 & 103 &, 198 & 95 &, 124 \\
\hline 48 &, 357 & 40 &, 256 & 6 &, 196 & 93 &, 124 \\
\hline 1 &, 341 & 51 &, 253 & 58 &, 187 & 101 &, 115 \\
\hline 52 &, 338 & 94 &, 244 & 8 &, 183 & 108 &, 113 \\
\hline 98 &, 333 & 97 &, 242 & 61 &, 182 & 57 &, 111 \\
\hline 109 &, 324 & 96 &, 241 & 110 &, 180 & 100 &, 103 \\
\hline 80 &, 324 & 42 &, 238 & 99 &, 170 & 15 &, 060 \\
\hline 50 &, 321 & 83 &, 236 & 79 &, 169 & 85 &, 028 \\
\hline 45 &, 321 & 86 &, 228 & 14 &, 168 & 81 &, 018 \\
\hline 54 &, 315 & 87 &, 224 & 12 &, 153 & 89 &, 009 \\
\hline 53 &, 294 & 47 &, 222 & 4 &, 152 & 39 &, 003 \\
\hline 102 &, 289 & 10 &, 221 & 49 &, 147 & 60 &,- 049 \\
\hline
\end{tabular}

Fonte: autores

Já no Quadro 2, os resultados do mesmo índice para o segundo eixo, inicialmente com o índice de 0,405 , são apresentados. Aqui, optamos por remover itens com correlações abaixo de 0,125 . É importante salientar que a mudança do limite do valor da correlação considerada para cada eixo, deve-se ao fato de que cada um destes subtestes apresenta diferentes variações de correlação com o instrumento integral, fazendo com que cada eixo deva ser analisado segundo os seus valores de mínimos e máximos. Isto é, para chegarmos ao valor definido como 
limite, testamos modelos com mais e menos itens sendo considerados, sendo então, mantido aquele que sustentou o maior valor de consistência interna para a menor quantidade de itens.

\begin{tabular}{|c|c|c|c|c|c|c|c|}
\hline Item & $\begin{array}{c}\text { Correlação } \\
\text { de item total }\end{array}$ & Item & $\begin{array}{l}\text { Correlação } \\
\text { de item total }\end{array}$ & Item & $\begin{array}{l}\text { Correlação } \\
\text { de item total }\end{array}$ & Item & $\begin{array}{l}\text { Correlação } \\
\text { de item total }\end{array}$ \\
\hline 23 & ,253 & 32 & ,206 & 33 & ,099 & 26 & ,014 \\
\hline 36 & ,237 & 25 &, 187 & 20 & ,098 & 27 &, 002 \\
\hline 29 & ,237 & 28 & , 163 & 30 & , 077 & 19 &,- 051 \\
\hline 24 & ,227 & 18 & ,138 & 35 & ,069 & 37 &,- 075 \\
\hline 22 & ,217 & 16 &, 133 & 17 &, 060 & & \\
\hline 21 & 215 & 31 &, 125 & 34 & 059 & & \\
\hline
\end{tabular}

Fonte: autores

Sendo assim, ao realizar o teste novamente, notou-se que o coeficiente aumentou para 0,542. Porém, observou-se também nos novos resultados, que se os itens 16 e 18 fossem removidos, o valor da consistência interna ainda poderia aumentar. Dessa forma, removendoos, o valor subiu para 0,602. Este valor, embora ainda não seja considerado como satisfatório para o instrumento individual, mesmo assim é maior do que a sua confiabilidade inicial. Dentro desta perspectiva, a decisão de remover a quantidade de 12 itens, parece acertada, pois os removidos atuam mantendo o índice menor do que se poderia alcançar sem eles presentes. Para o segundo eixo, das 22 questões, reduzimos para 10.

Finalmente, no Quadro 3 apresentamos os resultados para o terceiro eixo, onde novamente optamos por eliminar as correlações abaixo de 0,125 . Esta decisão mostrou que o coeficiente de valor 0,369 aumentou deste valor, para 0,393. Assim como no eixo anterior, a nova recombinação dos itens do subteste sugeriu que removendo ainda os itens 66 e 67 a confiabilidade poderia aumentar. Realizado este procedimento, o novo valor de consistência interna passou para 0,424 , reduzindo 8 itens e também melhorando sua confiabilidade.

\begin{tabular}{|c|c|c|c|c|c|c|c|}
\hline Item & $\begin{array}{c}\text { Correlação } \\
\text { de item total }\end{array}$ & Item & \begin{tabular}{|c|} 
Correlação \\
de item total \\
\end{tabular} & Item & $\begin{array}{c}\text { Correlação } \\
\text { de item total }\end{array}$ & Item & $\begin{array}{c}\text { Correlação } \\
\text { de item total } \\
\end{array}$ \\
\hline 76 & ,237 & 62 &, 149 & 72 &, 126 & 71 &, 062 \\
\hline 69 & 217, & 70 & , 145 & 67 &, 125 & 75 &, 062 \\
\hline 63 &, 165 & 73 & ,141 & 68 &, 118 & 64 & ,053 \\
\hline 74 & , 158 & 66 & , 140 & 65 & 091 & 77 &,- 084 \\
\hline
\end{tabular}

Após analisar cada um dos eixos particularmente e notar que, mesmo eliminando itens, seus índices se mantiveram semelhantes (e até mesmo maiores) aos seus valores iniciais, é necessário testar o instrumento reduzido de maneira integral, a fim de atestar que o TACB reduzido também possui consistência interna, quando esta é calculada para as 45 questões. Ao 
realizar este teste, constatamos que a confiabilidade inclusive teve seu valor aumentado em um centésimo, sendo então igual a 0,842 .

Verificados os índices de consistência interna dos subtestes e do instrumento geral, é necessário então testar o instrumento de 45 itens quanto ao seu poder de medida. Para isso, realizamos testes de correlação para cada subteste, e no fim, para o instrumento geral. Conforme exposto na seção anterior, correlaciona-se a quantidade de acertos dos respondentes para os 110 e para os 45 itens, a fim de verificar se o padrão de acertos segue tendência semelhante, o que é resumido no Quadro 4.

Quadro 4 - Correlações entre os índices de acertos do questionário integral e subtestes

\begin{tabular}{|c|l|l|}
\hline \multicolumn{3}{|c|}{ Correlação de Pearson } \\
\hline \multirow{3}{*}{ Subtestes } & Conteúdo da Ciência & $0,928^{* *}$ \\
\cline { 2 - 3 } & \begin{tabular}{l} 
Natureza da Ciência \\
\cline { 2 - 3 }
\end{tabular} & $\begin{array}{l}\text { Impacto da Ciência e Tecnologia na } \\
\text { Sociedade e Ambiente }\end{array}$ \\
\hline \multicolumn{2}{|c|}{ Questionário integral } & $0,818^{* *}$ \\
\hline$* *$ A correlação é significativa no nível 0,01 (bilateral). \\
\hline \multicolumn{2}{|c|}{ Fonte: autores. }
\end{tabular}

Pode-se observar que tanto os subtestes quanto o instrumento reduzido geral, demonstraram valores fortes de correlação. Estes resultados indicam que os dois instrumentos são semelhantes quanto à informação medida. Isto significa que o teste reduzido, com 45 questões, possui a mesma confiabilidade e poder de medida que o instrumento integral, com as suas 110 questões. Tal fato corrobora com a validade e fidedignidade desta versão reduzida do TACB, que passamos a denominar Teste de Alfabetização Científica Básica Simplificado (TACB-S). Os índices de acertos seguem a perspectiva do instrumento original, que tinha por base considerar um indivíduo alfabetizado cientificamente aquele que obtivesse acertos em aproximadamente $60 \%$ de cada subteste.

Embora o objetivo deste artigo seja a redução do TACB, é importante realizar também uma exposição sobre o padrão de respostas observado para este grupo de egressos do Ensino Médio. O grupo era heterogêneo, predominantemente do sexo feminino $(58,86 \%)$ e com a maioria dos participantes na faixa de idades entre 18 e 25 anos. Para a amostra pesquisada, apenas 51 pessoas $(36,17 \%)$ atingiram os valores mínimos de acertos para os três eixos. Esse resultado aproxima-se dos obtidos por Laugksch e Spargo (1996), bem como, por muitas das pesquisas apontadas na introdução deste texto, em nível nacional.

Outro fator percebido como relevante é o índice das questões que foram assinaladas com o ponto de interrogação, sugerido a ser utilizado quando o respondente desconhecesse a 
resposta. Das 110 questões, apenas 10 não constaram nos índices daquelas que em algum questionário foi marcada com esta codificação. Ou seja, quase todas foram objeto de dúvidas para algum respondente. Ao realizar uma análise qualitativa nos dez itens que mais foram assinalados com pontos de interrogação, notou-se que desse total, cinco eram questões da área da Física. (Itens 90, 78, 75, 85, 83, 84, 51, 48, 91 e 55).

Por fim, a análise dos erros em cada um dos subtestes demonstrou que a maior taxa de questões incorretas estava concentrada nos eixos que versam sobre a natureza da ciência e sobre o impacto da ciência e tecnologia na sociedade. Isto significa que o índice de acertos se concentrou majoritariamente no único eixo que possuía questões sobre conteúdo das disciplinas das Ciências da Natureza. Tal constatação pode ser um indício da natureza conteudista na qual o ensino de ciências pode ter sido abordado durante a educação básica destes egressos, padrão também percebido nas pesquisas supracitadas. Esta indicação, juntamente com o tipo de questões que obteve maior escore de "desconhecimentos", merece uma dedicação futura quanto à pesquisa. Tais observações são relevantes por apresentar um panorama da criticidade científica de indivíduos já fora do ambiente da educação básica. Por isso, sugere-se que investigações a fim de aprofundar os resultados, as discussões das causas dos mesmos e opções para atuar nesta realidade, sejam realizadas em estudos futuros.

\section{CONSIDERAÇões Finais}

Para fins de considerações, as análises objetivando a redução do questionário produziram resultados satisfatórios, simplificando-o de 110 para 45 itens. Este instrumento, embora seja composto por uma menor quantidade de questões, possui mesma confiabilidade e poder de medida que o instrumento integral. É importante salientar que foi respeitada a divisão do questionário original nos três eixos estruturantes da Alfabetização Científica, base na qual ele foi elaborado.

Conforme é possível conferir nos links externos ${ }^{1}$, o TACB-S inclui itens dos três subtestes, assegurando sua estrutura teórica inicial. Isto significa que a quantidade de informações que o questionário original examina nos respondentes, também pode ser encontrada, em escala menor, dentro do seu instrumento reduzido. A eficácia de tal afirmação foi constatada na análise das correlações entre os acertos para o TACB e o TACB-S, gerando

\footnotetext{
${ }^{1}$ TACB. Disponível em:<https://goo.gl/RijF47> TACB-S. Disponível em:<https://goo.gl/fS9yks>
} 
um índice de 0,932 , significando uma correlação muito forte entre o instrumento integral e sua versão que chamamos de simplificada.

As questões referentes ao eixo "entendimento dos conteúdos da ciência" são as de 1 a 3, 14 a 26 e as de 35 a 45. O eixo "entendimento da natureza da ciência" é composto pelas questões de 4 a 13, e por fim, o eixo "entendimento do impacto da ciência e tecnologia na sociedade e ambiente" compreende as questões da 27 até a 34.

Acreditamos que este trabalho poderá colaborar com pesquisadores e professores que desejam mensurar níveis de Alfabetização Científica a partir de um instrumento que já é validado e referenciado em contextos internacionais, porém, por desafios de natureza temporal ou de fadiga dos respondentes, a sua aplicação em grande escala poderia ser, até então, inviabilizada. O TACB-S possui 45 itens válidos e fidedignos, que podem servir de base para estes diversos fins da prática escolar e acadêmica.

Recomenda-se que este instrumento seja aplicado nos mais diversos contextos, desde alunos regulares das escolas, para verificar, por exemplo, o crescimento em sua Alfabetização Científica antes e depois de um semestre ou ano letivo, ou em egressos do Ensino Médio, professores, cidadãos de modo geral, enfim; deseja-se que esta proposta de mensuração deste fenômeno possa contribuir com a área, auxiliando na apresentação de diagnósticos sobre a Educação em Ciências do contexto brasileiro.

Por fim, é sugerido também que o TACB-S seja traduzido para o inglês e um teste piloto com alunos estrangeiros seja realizado, a fim de atestar seus índices de confiabilidade e poder de medida também para um público-alvo advindo de uma realidade escolar diferente da vivenciada no Brasil.

\section{REFERÊNCIAS}

ANDRADE, Ê. R.; SCHEUER, C. Análise da eficácia do metilfenidato usando a versão abreviada do questionário de conners em transtorno de déficit de atenção/hiperatividade. Arquivos de Neuro-Psiquiatria, São Paulo, v. 62, n. 1, p. 81-85, Mar. 2004.

AULER, D.; DELIZOICOV, D. Alfabetização científico-tecnológica para quê?. Ensaio Pesquisa em Educação em Ciências (Belo Horizonte), v. 3, n. 2, p. 122-134, 2001.

BARAM-TSABARI, A.; YARDEN, A. Text genre as a factor in the formation of scientific literacy. Journal of research in science teaching, v. 42, n. 4, p. 403-428, 2005.

BITTAR, D. B.; PEREIRA, L. V.; LEMOS, R. C. A. Sistematização da assistência de enfermagem ao paciente crítico: proposta de instrumento de coleta de dados. Texto Contexto Enfermagem, v. 15, n. 4, p. 617-628, 2006. 
BROSSARD, D.; SHANAHAN, J. Do they know what they read? Building a scientific literacy measurement instrument based on science media coverage. Science Communication, v. 28, n. 1, p. 47-63, 2006.

CAMARGO, A. N. B.; PILAR, F. D.; RIBEIRO, M. E. M.; FANTINEL, M.; RAMOS, M. G. Alfabetização Científica: A evolução ao Longo da formação de Licenciandos Ingressantes, Concluintes e de Professores de Química. Momento - Diálogos em Educação, v.20, n.2, p. 19-29, 2011.

CAMARGO, B. V.; BARBARÁ, A.; BERTOLDO, R. B. Um instrumento de medida da dimensão informativa da representação social da aids. Jornada Internacional, v. 4, p. 1385$1395,2005$.

CARVALHO, A.M.P. E TINOCO, S.C. O Ensino de Ciências como 'enculturação'. In: Catani, D.B. e Vicentini, P.P., (Orgs.). Formação e autoformação: saberes e práticas nas experiências dos professores. São Paulo: Escrituras, 2006.

CHASSOT, A. Alfabetização científica: uma possibilidade para a inclusão social. Revista Brasileira de Educação, n. 22, p. 89-100, 2003;

CHASSOT, A. Alfabetização Científica - Questões e desafios para a educação. Ijuí, Editora da Unijuí, ed. 1, 2011.

CHIN, C. First-year Pre-service Teachers in Taiwan-Do they enter the teacher program with satisfactory scientific literacy and attitudes toward science? International Journal of Science Education, v. 27, n. 13, p. 1549-1570, 2005.

CUNHA, R. B. Alfabetização científica ou letramento científico?: interesses envolvidos nas interpretações da noção de scientific literacy. Revista Brasileira de Educação, Rio de Janeiro, v. 22, n. 68, p. 169-186, 2017.

FIGUEIREDO, V. L. M.; MATOS, V. L. D.; PASQUALI, L.; FREIRE, A. P. Propriedades psicométricas dos itens do teste WISC-III. Psicologia em estudo. v.13, n.3, p. 585-592. 2008.

FRANCA, C.; COLARES, V. Validação do National College Health Risk Behavior Survey para utilização com universitários brasileiros. Ciência e Saúde Coletiva, v. 15, p. 1209-1215, 2010.

HAIR, J.; BLACK, W.; BABIN, B.; ANDERSON, R.; TATHAM, R. Multivariate Data Analysis. $6^{\mathrm{a}}$ ed. Upper Saddle River, NJ: Pearson Prentice Hall, 2006.

LAUGKSCH, R. C.; SPARGO, P. E. Construction of a paper-and-pencil Test of Basic Scientific Literacy based on selected literacy goals recommended by the American Association for the Advancement of Science. Public Understanding of Science, v. 5, p. 331-359, 1996.

LAUGKSCH, R. C.; SPARGO, P. E. Scientific Literacy of Selected South African Matriculants Entering Tertiary Education: A Baseline Survey. South African journal of science, v. 95, p. 427-432, 1999. 
LIMA, M. S.; WEBER, K. C. Reflexões acerca das definições e mensuração de níveis de letramento científico. Anais do Congresso Nacional de Educação - CONEDU. 2017. Disponível em:< https://editorarealize.com.br/revistas/conedu/trabalhos/ TRABALHO_EV056_MD1_SA18_ID3162_11082016105336.pdf >. Acesso: Jun. 2018.

MAMEDE, M.; ZIMMERMANN, E. Letramento científico e CTS na formação de professores para o ensino de ciências. Enseñanza de las Ciencias, n. Extra, p. 1-4, 2005.

MILLER, J. Scientific literacy: a conceptual and empirical review. Daedalus, v. 112, n. 2, p. 29-48, 1983.

MOREIRA, M. A.; ROSA, P. R. S. Uma introdução à pesquisa quantitativa em Ensino. Porto Alegre: Edição dos Autores, 2007.

MORTIMER, E.F. E MACHADO, A.H. A Linguagem em uma Aula de Ciências, Presença Pedagógica, v.2, n.11, 49-57, 1996.

MURCIA, K.; SCHIBECI, R. Primary student teachers' conceptions of the nature of science. International journal of science education, v. 21, n. 11, p. 1123-1140, 1999.

NASCIMENTO-SCHULZE, C. M. Um estudo sobre alfabetização científica com jovens catarinenses. Psicologia: teoria e prática, v. 8, n. 1, 2006.

ÖZDEM, Y. Y.; ÇAVAŞ, P.; CAVAS, B.; ÇAKIROĞLU, J; ERTEPINAR, H. An investigation of elementary students' scientific literacy levels. Journal of Baltic Science Education. V.9 n. 1, p. 6-19, 2010.

PASQUALI, L. Psicometria: teoria dos testes na psicologia e na educação. Petrópolis: Editora Vozes, 2017.

RIVAS, M. I. E. Avaliação do nível de Alfabetização Científica de estudantes de biologia. Trabalho de conclusão de curso. Graduação em biologia. Universidade Federal do Rio Grande do Sul - UFRGS, 2015;

SASSERON, L. H.; CARVALHO, A. M. P. Almejando a alfabetização científica no ensino fundamental: a proposição e a procura de indicadores do processo. Investigações em ensino de ciências, v. 13, n. 3, p. 333-352, 2008.

SASSERON, L. H.; CARVALHO, A. M. P. Alfabetização Científica: uma revisão bibliográfica. Investigações em Ensino de Ciências, v.16, n.1, p. 59-77, 2011.

SOUZA, A. C.; ALEXANDRE, N. M. C.; GUIRARDELLO, E. B. Propriedades psicométricas na avaliação de instrumentos: avaliação da confiabilidade e da validade.

Epidemiologia e Serviços de Saúde, v. 26, p. 649-659, 2017.

SOUZA, C. A.; BASTOS, F. P.; ANGOTTI, J. A. P. Cultura científico-tecnológica na educação básica. Ensaio Pesquisa em Educação em Ciências (Belo Horizonte), v. 9, n. 1, p. 76-88, 2007.

VIDOR, C. B.; COSTA, S. S. C. ; SILVA, A. M. M.; RAMOS, M. G. Avaliação do nível de Alfabetização Científica de professores da educação básica. In: VII Encontro Nacional de 
Pesquisadores em Ensino de Ciências, 2009. Anais do VI ENPEC. Florianópolis: ABRAPEC, 2009. Disponível em:

http://www.foco.fae.ufmg.br/viienpec/index.php/enpec/viienpec/paper/view/1047. Acesso em: jun. 2018.

Recebido em: 27 de agosto de 2018.

Aprovado em: 16 de setembro de 2018. 